\title{
Mathematical Modelling of Infra-Red Evaporation Characteristics of Wheat Straw Black Liquor
}

\author{
Surendra Pratap Singh ${ }^{1}$, Mohammad Jawaid ${ }^{2 *}$, Bhoomika Yadav $^{3}$ and \\ Mohd Supian Abu Bakar ${ }^{2}$ \\ ${ }^{1}$ Pulp \& Paper Research Institute, Rayagada, Odisha, 765001, India \\ ${ }^{2}$ Laboratory of Biocomposite Technology, Institute of Tropical Forestry and Forest Products \\ (INTROP) Universiti Putra Malaysia, 43400 UPM, Serdang, Selangor, Malaysia \\ ${ }^{3}$ Department of Material Science and Metallurgical Engineering, University Institute of Engineering and \\ Technology, CSJM University, Kanpur, 208024, India
}

\begin{abstract}
Infrared (IR) evaporation characteristics of Weak Soda Black Liquor (WSBL) were determined at five different temperatures of $80,90,100,110$ and $120^{\circ} \mathrm{C}$. The effect of constant temperature on evaporation rate and moisture content (on a dry basis) of $1.5 \mathrm{gm}$ approx. WSBL tests were contemplated and required a careful time frame of IR dissipation to vanish the dampness content at a different consistent temperature. The dissipation rate expanded with expanding infrared temperature. Therefore, different numerical models, such as Page and Logarithmic, Henderson, Pabis and Lewis, were utilised to fit the experimental data properly. A Gaussian model equation was developed for evaporation rate and moisture fraction of black liquor. The probable empirical parameters, along with the relating of reduced chi-square $\left(X^{2}\right)$, Residual Sum of Square (RSS), and coefficients of determination (adjusted $R^{2}$ ) from non-linear regression analysis of all the numerical model equations, were examined. In addition, the effect of evaporation temperature on the water removal rate, the effective diffusion coefficient and activation energy were also estimated. The effective diffusion coefficient ranges from $2.67 \times 10^{-10} \mathrm{~m}^{2} / \mathrm{s}$ to $10.4 \times 10^{-10} \mathrm{~m}^{2} / \mathrm{s}$, and the activation

ARTICLE INFO

Article history:

Received: 16 April 2021

Accepted: 28 July 2021

Published: 22 October 2021

DOI: https://doi.org/10.47836/pjst.29.4.33

E-mail addresses: energy was $39.19 \mathrm{~kJ} / \mathrm{mol}$. The statistical indicators (chi-square and determination coefficient) showed that the Decay model equation and Gaussian equation are the most suitable models for describing the evaporation process of WSBL.
\end{abstract}

spsinghbh@gmail.com (Surendra Pratap Singh)

jawaid@upm.edu.my (Mohammad Jawaid)

bhoomika@iitk.ac.in (Bhoomika Yadav)

supian7779@gmail.com (Mohd Supian Abu Bakar)

* Corresponding author

Keywords: Biomass, black liquor, evaporation, viscosity, wheat straw 


\section{INTRODUCTION}

In the soda pulping process, the fibres are separated from the agricultural residue. Lignin, hemicelluloses, and low molecular weight carbohydrates are removed by agricultural pulping residue in the cooking chemical solution, which contains active chemicals and caustic soda at high temperature and pressure (approximately 165 to $170^{\circ} \mathrm{C}$ and 6 to $8 \mathrm{~kg}$ / $\mathrm{cm}^{2}$ ) in the digester. The digested material coming out from the blow tank contains both the spent cooking liquor and the fibres. The spent liquor of dark brownish colour is called black liquor (Do et al., 2020). The back liquor contains a mixture of inorganic chemicals $(\mathrm{NaOH})$ and a large proportion of organic chemicals, mainly lignin (Alriols et al., 2009; Hurter, 1991). The weak black liquor normally has dry solids content of $14 \%$ to $18 \%$ (approximately) and is not suitable for direct use in the chemical recovery furnace as fuel (Bajpai, 2017). The main purpose of evaporation of black liquor is to increase the dry solids content by evaporating excess water until reaching a solids content that is suitable for burning in the chemical recovery furnace (Goodell \& Point, 1933). Since there is probable danger of smelt explosions, the dry solids content of heavy black liquor (HBL) should be a minimum of $58 \%$. Nowadays, the dry solids content of $70 \%$ to $75 \%$ is normal, and even $80 \%$ to $85 \%$ is the target value for the dry solids content with wood to increase the chemical recovery furnace thermal efficiency (Naqvi et al., 2010; Nasir et al., 2020; Low \& Ong, 2020 ), with agricultural residues black liquor, is normally in the range of $60 \%$ to $65 \%$.

In conventional evaporation of black liquor displays two distinct stages of evaporation. The preliminary stage of the evaporation process is similar to the evaporation of water from the free surface. The evaporation rate is not dependent on the water content of the black liquor. This evaporation stage is known as the "Constant Rate Period (CRP)" in the evaporation of black liquor. However, through the removal of freely available water from black liquor, the evaporation rate decreases, then this stage of evaporation is known as the "Falling Rate Period (FRP)". The water quantity removed during this interval is comparatively small compared to the initial stage and the time engaged was extensive. The longer time interval required during the falling rate period in conventional evaporation means excess consumption of energy (Mujumdar, 2007; Nasir et al., 2020). Generally, the usual evaporators used in the paper industry are falling film, rising film and forced circulation evaporators (Haghsheno \& Kouhikamali, 2020).

Evaporation is a complex thermal process in which unsteady heat and moisture transfer co-occur. From an engineering point of view, it is better to understand this complex process's controlling parameters. Mathematical models of the drying processes are used to design new or improving existing evaporation systems or even control the evaporation process. The major disadvantages of these evaporators are the long evaporation time during the evaporation and low energy efficiency. In recent years, infra-red and microwave evaporation has gained attention as an optional evaporation/drying method in the food and 
beverages industries (Darvishi et al., 2013; Datta \& Anantheswaran, 2001; Hatibaruah et al., 2013; Sandu, 1986). However, there has been not much information available on infra-red evaporation characteristics of soda black liquor, which is a by-product of the agricultural residues-based pulp and paper industry. The infra-red heating process may extensively improve the evaporation quality of black liquor. Reducing energy consumption and period using infra-red in black liquor evaporation may significantly contribute to the pulp and paper industry. Thus, this present study aims to explore the influence of infra-red temperature levels on evaporation kinetics and establish an appropriate model for infra-red evaporation of weak soda black liquor. It is also helps to design an evaporator equipped with an infrared heating facility to enhance process and energy efficiency for the pulp and paper industry.

\section{MATERIALS AND METHODS}

\section{Analysis of Black Liquor}

From Table 1, the TAPPI methods (TAPPI, Atlanta, USA) and provisional methods have described the physico-chemical properties from black liquor, where the $\mathrm{pH}$ value and total dissolved solids in black liquor have been measured after constant weight condition has obtained at 24 hours preservation. The inorganic matter was shown at a combustion temperature of $525 \pm 3^{\circ} \mathrm{C}$, while the organic matter was figured out as the distinction between

Table 1

Characterisation of soda black liquor

\begin{tabular}{lcc}
\hline Particulars & Quantity & Test Methods \\
\hline Chemical compositions & & \\
\hline pH at room temp. & 11.9 & - \\
Specific gravity $/ 20^{\circ} \mathrm{C}$ & 1.04 & TAPPI T-625 CM-85 \\
Total solids, \%w/w & 8.1 & TAPPI T-625 CM-85 \\
Residual Active Alkali, g/L as $\mathrm{NaOH}$ & 7.32 & TAPPI T-625 CM-85 \\
Total alkali, g/L as $\mathrm{NaOH}$ & 18.5 & TAPPI T-625 CM-85 \\
Silica, as $\mathrm{SiO} 2, \% \mathrm{w} / \mathrm{w}$ & 3.76 & TAPPI T-625 CM-85 \\
Inorganics, \%w/w & 32.35 & TAPPI T211 om-93 \\
\hline Elemental composition & & \\
\hline Carbon, \% w/w & 30.1 & CHNS Analyser (Instrumental method) \\
Hydrogen, \%w/w & 4.15 & CHNS Analyser (Instrumental method) \\
Oxygen, \%w/w & 36.85 & By difference \\
Nitrogen, \%w/w & 1.11 & CHNS Analyser (Instrumental method) \\
Sodium, \%w/w & 19.5 & AAS (Instrumental method) \\
Calcium, \%w/w & 3.46 & AAS (Instrumental method) \\
Potassium, \%w/w & 3.08 & AAS (Instrumental method) \\
CV $(\mathrm{MJ} / \mathrm{kg}$ ) & 11.63 & Bomb calorimeter \\
\hline
\end{tabular}


inorganic matter and total dissolved solids. Furthermore, the analyses of Carbon, Hydrogen, Nitrogen, and Sulphur (CHNS) was performed with CHNS analyser (Vario, Model: E III). The elemental analysis was performed by Atomic Absorption Spectra (AAS) (Perkin Elemer, Model: 800) after alkaline fusion by ASTM D368296. The calorific value analyses of oxygen content in the black liquor solids were determined using a bomb calorimeter (Toshniwal Technologies Pvt. Ltd., New Delhi, India). The characteristics of the soda black liquor sample are summarised in Table1.

\section{Infrared Drying Experiments}

Weak black liquor samples of 12 to $14 \%$ solids content used in the evaporation experiments were collected from M/S Mohit Paper Mills Ltd., Bijnor (U.P), India. An IR moisture analyser (Model no. XM-120, Precisa Gravimetrics AG, 8953 Dietikon, Switzerland) was used for the present study. The IR moisture analyser is equipped with the facility to adjust temperature levels at $90,100,110$ and $120^{\circ} \mathrm{C}$. The dimensions of the IR moisture analyser (Instrument housing, $\mathrm{W} \times \mathrm{H} \times \mathrm{D} \mathrm{mm}$ ) used for drying were $210 \mathrm{~mm}(\mathrm{~W}) \times 340 \mathrm{~mm}(\mathrm{D}) \times$ $170 \mathrm{~mm}(\mathrm{H})$.

The evaporation trial was carried out for a $1.2 \mathrm{gm}$ (approx.) sample at four different infra-red temperature levels viz., 90,100,110 and $120^{\circ} \mathrm{C}$. During experiments, each sample was put on the stationary sample pan filled with $2 \mathrm{~mm}$ sand to avoid skin formation during evaporation. The pan was placed in the centre of the moisture analyser. The XM-120 infrared (IR) moisture analyser can be used for reliable and quick determination of the moisture content of liquid, semisolid and solid substances according to the thermo-gravimetry method. The moisture content of the black liquor sample was calculated according to the early moisture content and the mass loss during evaporation. The moisture loss was determined by thermo-gravimetric analysis of the sample at one-minute intervals. For better quality, evaporation was resumed until the moisture content of the black liquor sample concentrated to about 2.5 to $3 \%$. The TAPPI standards obtained the moisture content of the completely dry black liquor samples. Experiments were carried out in triplicate to minimise the possible errors.

In the present investigation, a radiator is used as drying equipment to transmit electromagnetic radiation in short to medium frequency wave IR radiation (wavelength in the range of 2 to $3.5 \mathrm{~nm}$, as specified in the

Table 2

The technical specification of the IR moisture analyser apparatus

\begin{tabular}{lc}
\hline \multicolumn{1}{c}{ Properties } & Range \\
\hline Power consumption max (VA) & $470 \mathrm{VA}$ \\
Frequency $(\mathrm{Hz})$ & $50 \mathrm{~Hz}$ \\
Temperature range $/ \mathrm{steps}\left({ }^{\circ} \mathrm{C}\right)$ & $30-230^{\circ} \mathrm{C} / 1^{\circ} \mathrm{C}$ \\
Graduation & $1{ }^{\circ} \mathrm{C}$ \\
Time switch (range) & $240 \mathrm{~min}$ \\
Weighing range $(\mathrm{g})$ & $124 \mathrm{~g}$ \\
Smallest sample weight $(\mathrm{g})$ & $0.2 \mathrm{~g}$ \\
Pan Size $[\varnothing$ mm $]$ & 100 \\
Readability $(\mathrm{g})$ & $0.001 \mathrm{~g}$ \\
Moisture Analysis Readability & \\
$(\%)$ & 0.001 \\
\hline
\end{tabular}


equipment manual). The technical specification of the IR moisture analyser apparatus (PRECISA, Series 330 XM - Model XM60, Switzerland) was displayed in Table 2.

\section{Determination of Evaporation Rate and Diffusion Co-efficient}

In the present investigation, the variables on the moisture fraction effect of black liquor and the evaporation rate were studied (Thakor et al., 1999). The moisture fraction $(X)$ of black liquor samples was calculated using Equation 1.

$$
x=\frac{M_{t}-M_{e}}{M_{o}-M_{e}} \approx \frac{M_{t}}{M_{o}}
$$

Equation $1 x$ is the moisture fraction of black liquor and dimensionless term: the initial moisture content, $M_{o}$ of the black liquor (gm water/gm solids content). Meanwhile, the moisture content of black liquor at any time $(t)$, (gm water/gm solids content) was indicated as $M_{t}$ and $M_{o}$ are balanced in the moisture content of black liquor sample (gm water/g solids content). The value of $M_{e}$ is negligible compared with $M_{t}$ or $M_{o}$ specifically for IR evaporation. Thus, $M_{e}$ was neglected and is assumed as zero. The overall evaporation rate (ER) was characterised as the variation of moisture fraction in a unit time ( $t$ ), using Equation 2.

$$
E R=\frac{d x}{d t}
$$

The general Gaussian model equation is given by Equation 3,

$$
y=E R=\sum_{i=1}^{n} a_{i} e^{\left[-\left(\frac{x-b_{i}}{c_{i}}\right)^{2}\right]}
$$

Where, $a$ is the amplitude, $b$ is the centroid (location), $c$ is related to the peak width, $n$ is the number of peaks to fit, and $1 \leq n \leq 8$ (Guo 2011).

The determination of effective diffusivity of the evaporation of weak black liquor has occurred in both the Constant Rate Period (CRP) and Falling Rate Period (FRP). Therefore, Fick's second law of diffusion displayed in Equation 4,

$$
\frac{\partial x}{\partial t}=\nabla\left[D_{e f f}(\nabla x)\right]
$$

Subsequently, the internal mass transfer element has controlled the evaporation process. Therefore, Equation 4 defined the evaporation process and determined the experimental data during the Falling Rate Period (FRP). Assuming that the moisture migrates barely by diffusion and no shrinkage occurred. Therefore, the actual diffusion co-efficient is constant, 
and the water evaporation is only from the free surface of the black liquor sample, then the empirical solution for the Ficks second law of diffusion can be described as Equation 5 (Crank, 1975),

$$
X=\frac{8}{\pi^{2}} \sum_{n=0}^{\infty} \sum \frac{1}{(2 n+1)} \exp \left[-(2 n+1)^{2} \pi^{2} \frac{D_{e f f} t}{r^{2}}\right]
$$

Where $D_{\text {eff }}$ is moisture diffusivity $\left(\mathrm{m}^{2} / \mathrm{s}\right), r$ is the average radius of the sand particles $(\mathrm{m})$, and $t$ is time ( $\mathrm{sec}$ ). Equation 6 could be additionally streamlined by taking the initial term of the arrangement as (Tütüncü \& Labuza, 1996).

$$
X=\frac{8}{\pi^{2}} \exp \left[-\pi^{2} \frac{D_{e f f}}{r^{2}}\right]
$$

Taking natural logarithm both sides, Equation 6 becomes Equation 7,

$$
\operatorname{In}(X)=\operatorname{In}\left(\frac{8}{\pi^{2}}\right)-\left(\frac{\pi^{2} D_{e f f}}{4 r^{2}} t\right)
$$

The effective moisture diffusivity $D_{\text {eff }}$ was analysed by plotting experiential evaporation data in $\ln (X)$ versus time (t). From Equation 7, a plot of $\ln (X)$ versus time $(\mathrm{t})$ gives a straight line with a slope $k_{o}$ as Equation 8,

$$
k_{0}=\frac{\pi^{2} D_{e f f}}{4 r^{2}}
$$

In addition, the influence of temperature on effective diffusivity $\left(D_{\text {eff }}\right)$ can be illustrated by Arrhenius Equation 9 (Madamba et al., 1996; Sanjuán et al., 2003),

$$
D_{\text {eff }}=D_{0} \exp \left(-\frac{E_{a}}{R T}\right)
$$

Therefore, from Equation 9, $E_{a}$ is activation energy $(\mathrm{kJ} / \mathrm{mol})$. Meanwhile, $D_{o}$ is the preexponential factor of the Arrhenius equation $\left(\mathrm{m}^{2} / \mathrm{s}\right), R$ is the ideal gas constant $(\mathrm{kJ} / \mathrm{mol} \mathrm{K})$, and $\mathrm{T}$ is the evaporation temperature $(\mathrm{K})$. Further, the value $E_{a} / R$ was obtained by plotting $\ln \left(D_{\text {eff }}\right)$ versus the mutual of temperature $(1 / \mathrm{T})$.

\section{Statistical and Mathematical Modelling of the Evaporation Curve}

The experimental evaporation data were tested to find the most appropriate model among seven different models defining evaporation/drying process put forward by several authors. Furthermore, the seven mathematical model equations effectively utilised in other 
exploration were utilised to assess the relationship between evaporation time (evaporation curve) and moisture fraction $(X)$ of black liquor using a non-linear regression procedure (Table 3).

The test data in this present study was additionally fitted with other regression equations and has indicated a high degree of fitting at the non-linear regression method. The non-linear regression method, was constructed by the Levenberg-Marquardt (LM) algorithm, where it has extensively used algorithm in non-linear least square fitting. The Levenberg-Marquardt algorithm, starting with some initial parameter values, minimises RSS by presenting a series of repetitions on the parameter values and computing RSS at every stage. Therefore, to perform this method, the initial partial derivatives were analysed for all values of the input parameters (Ranganathan, 2004).

The coefficients were estimated using OriginPro 9 software (The OriginLab Corporation, USA) according to the non-linear least square method. The three parameters reduced chi-square $\left(X^{2}\right)$, residual sum of square (RSS), and determination coefficient $\left(R^{2}\right)$ were used to evaluate the deviation between the predicted values and the experimental data for the dependent variable. These can be used for comparing various models representing the same dependent variable. The fitness parameters among distinct models were performed at $p<0.05$ of variance (ANOVA) analysis (Table 4). Thus, the best model used for defining the evaporation characteristics of black liquor samples under infra-red (IR) radiation heating was preferred with the lowest reduced data of chi-square $\left(X^{2}\right)$, residual sum of square (RSS) and highest coefficient of the determinant $\left(R^{2}\right)$ or adjusted $R$-squared $\left(R_{a d j}^{2}\right)$. The statistical values were calculated with below Equations 10-13 as,

$$
\begin{aligned}
& X^{2}=\sum_{i=1}^{n} \frac{\left(X_{i_{\text {exp }}}-X_{i_{\text {pred }}}\right)}{X_{i_{\text {exp }}}} \\
& R S S=\sum_{i=1}^{n}\left(X_{i_{\text {exp }}}-X_{i_{\text {pred }}}\right)^{2}
\end{aligned}
$$

Table 3

Mathematical models of the evaporation curves of black liquor sample

\begin{tabular}{clrr}
\hline No. & \multicolumn{1}{c}{ Equations } & Model name & References \\
\hline 1. & $X=\exp (-k t)$ & Lewis & (Bruce, 1985) \\
2. & $X=\exp \left(-k t^{n}\right)$ & Page & (Chen, 2009) \\
3. & $X=\exp \left(-(k t)^{n}\right)$ & Modified Page-I & (Overhults et al., 1973) \\
4. & $X=a \exp (-k t)$ & Henderson and Pebis & (Bhargava, 1966) \\
5. & $X=1+a t+b t^{2}$ & Wang and Singh & (Ahou et al., 2014) \\
6. & $X=a \exp (-k t)+\mathrm{c}$ & Logarithmic & (Yagcioglu et al., 1999) \\
7. & $X=a+\mathrm{b}+\left(0.25 c^{2} t^{2}\right)-\left(a^{0.5} c t\right)$ & Decay & Present study \\
\hline
\end{tabular}




$$
\begin{aligned}
& R^{2}=1-\frac{\sum_{i=1}^{n}\left(X_{i_{\text {exp }}-} X_{i_{\text {pred }}}\right)^{2}}{\sum_{i=1}^{n}\left(X_{i_{\text {exp }}}-\bar{X}\right)^{2}} \\
& R_{a d j}^{2}=1-\frac{\left(1-R^{2}\right)(n-1)}{n-p}
\end{aligned}
$$

Where, $\bar{X}$ is the average value of the experimental moisture ratio, $X i_{\text {pred }}$ and $X i_{\text {exp }}$ are predicted, and experimental moisture ratios, respectively, $p$ is the number of evaporation constants, and $n$ is the number of observations.

\section{RESULTS AND DISCUSSION}

\section{Analysis of Evaporation Curves and Model Fitting}

The changing of the moisture fraction versus evaporation time for black liquor samples is shown in Figure 1. It was shown that the moisture fraction is affected by the isothermal temperature and evaporation time of black liquor. Moreover, from Figure 1, the evaporation time was significantly reduced from 9.5 to 4 minutes as the temperature increases; besides, an increase of the temperature has shortened the evaporation duration up to 55\%. From the observation from the Figure 1 curve, the moisture fraction constantly decreases with evaporation time, and no constant evaporation rate period exists.

These observations are validated with previous literature studies on the evaporation/ drying of organic compounds (Gögüs \& Maskan, 2001; Meziane et al., 2006; Amin et al., 2019). As shown in Figure 2, the rate of moisture loss of black liquor was high at the initial

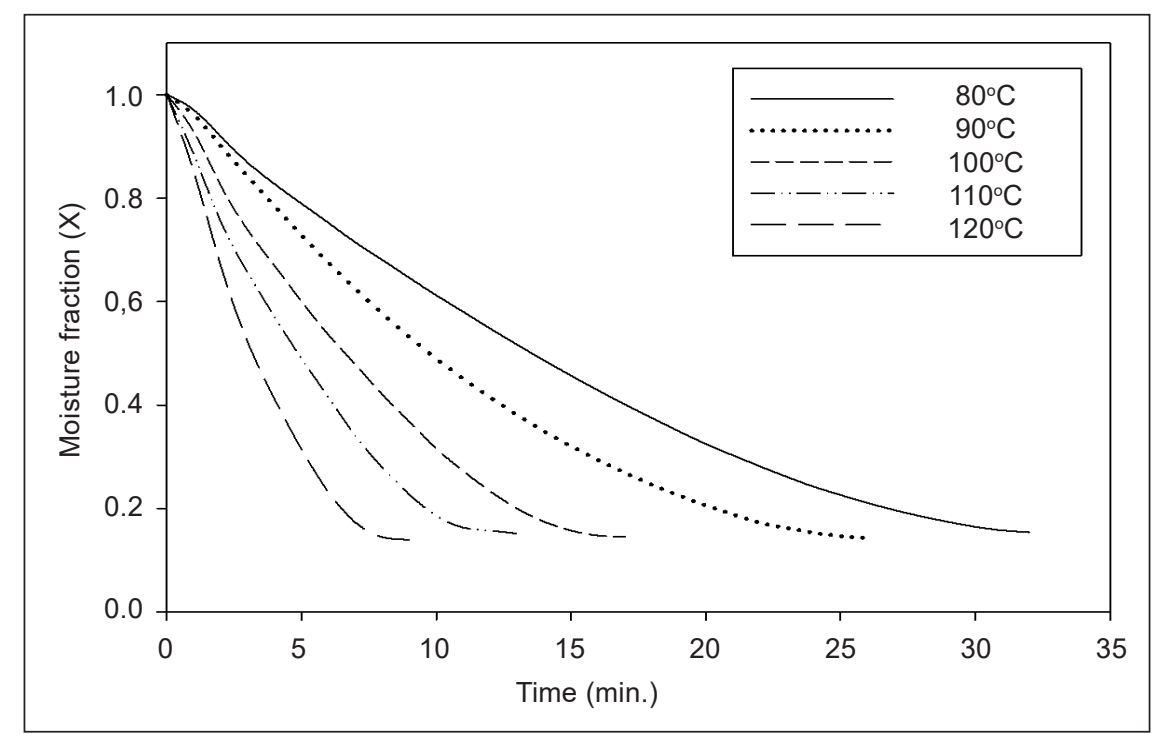

Figure 1. Evaporation curves of soda black liquor at different temperatures 


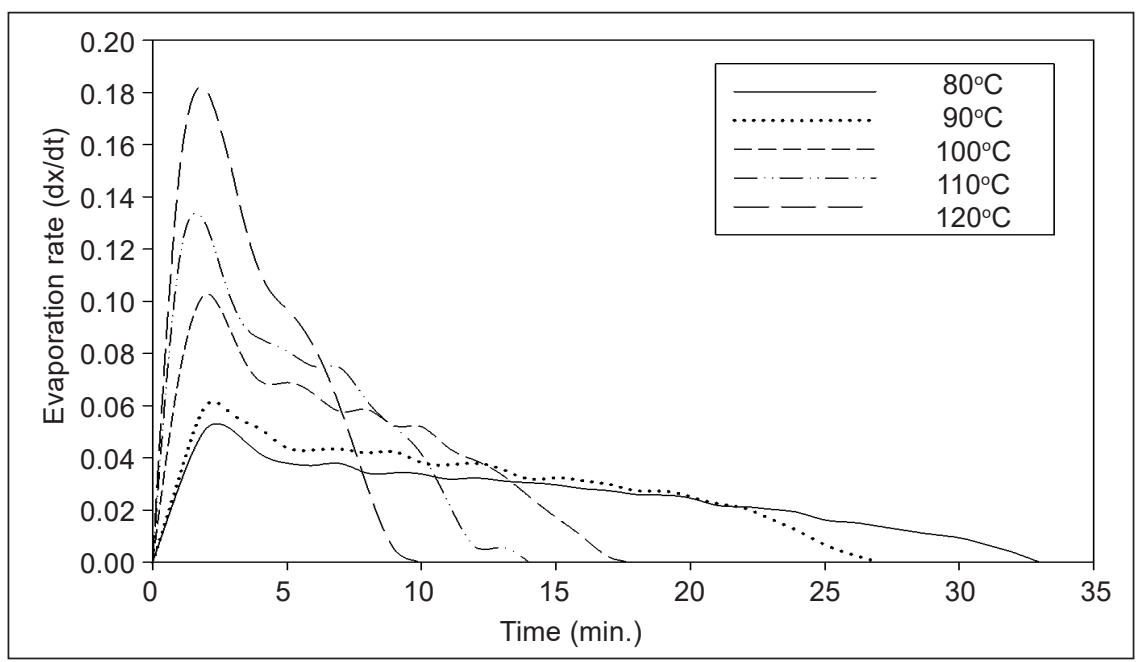

Figure 2. Variation of evaporation rate with evaporation time of black liquor

stage. In contrast, equally two-thirds of the time has been spent removing the last onethird of the moisture content due to the slow diffusion process. However, the black liquor evaporation at a higher temperature is significantly less. Thus, the overall evaporation time of the black liquor was reduced significantly with the increase in temperature. Thus, the physical mechanism prevailing in moisture transfer of the black liquor sample has resulted in a falling rate period (FRP) and internal diffusion throughout the evaporation process. Moreover, other studies also have reported similar behaviour (Karlsson, 2020).

From Figure 2, every plot has two stages in which evaporation progresses, where the evaporation rate rapidly increases and then slowly decreases. Otherwise, from this present study, it has been found that the evaporation rate will decrease corresponding to the period or with the reduction of the moisture fraction. Furthermore, the moisture fraction of the black liquor is high in the initial phase of evaporation, which has resulted in greater absorption of IR radiation and a higher evaporation rate due to the higher moisture diffusion. As the evaporation progresses, the reduction in moisture fraction in the black liquor causes a decrease in the absorption of IR radiation, and the results of evaporation rate fall tremendously. A higher evaporation rate was obtained at higher Infrared output temperature. Thus, the infrared output temperature had a significant consequence on the evaporation rate of black liquor. In comparison, the total evaporation times required to reach the final moisture content were $33,27,18,14$, and 10 minutes at $80,90,100,110$, and $120^{\circ} \mathrm{C}$, respectively, as shown in Figure 1. Meanwhile, the evaporation time until moisture fraction up to 0.5 was $3.3,4.8,6.6,9.6$, and 15.5 minutes at $120,110,100,90$, and $80^{\circ} \mathrm{C}$, respectively. The evaporation rates were more at the beginning of the evaporation process due to the evaporation of moisture from black liquor and then reduced with reducing moisture content (Figure 2). 
The thin layer evaporation model equation of the infra-red evaporation process was suitable for the preliminary evaluation and constant evaporation stages. It can convey the important equation characteristic parameters such as heat, thermal diffusivity, moisture diffusivity, and mass transfer coefficients. Moreover, various models have been advised to depict the rate of moisture loss throughout the thin layer drying process of organic materials. Therefore, this present study has nominated seven mathematical models (Table 3) of the evaporation curves used in previous studies. Besides, the non-dimensional in Equation 1 has been used to compile data in experimental of moisture fraction. Meanwhile, the regression analysis was prepared for seven distinct thin layer drying models by correlating the dimensionless moisture fraction $(X)$ for $80,90,100,110$, and $120^{\circ} \mathrm{C}$ temperatures and evaporation time. The statistical analysis values obtained from fitting the experimental data to the widely used semi-theoretical thin layer models (Table 3) are presented in Table 4.

Table 4

Fitness of different models for IR evaporation of black liquor

\begin{tabular}{|c|c|c|c|c|c|c|}
\hline Equation & Temp.(K) & & & Reduced, $X^{2}$ & RSS & Adj. $R^{2}$ \\
\hline \multirow[t]{6}{*}{ Lewis } & & $\mathbf{k}$ & & & & \\
\hline & $353 \mathrm{~K}$ & 0.05452 & & $6.47 \mathrm{E}-04$ & 0.02005 & 0.99062 \\
\hline & $363 \mathrm{~K}$ & 0.07387 & & $5.11 \mathrm{E}-04$ & 0.01328 & 0.9932 \\
\hline & $373 \mathrm{~K}$ & 0.11233 & & $6.35 \mathrm{E}-04$ & 0.01079 & 0.99203 \\
\hline & $383 \mathrm{~K}$ & 0.15209 & & 4.39E-04 & 0.0057 & 0.99463 \\
\hline & $393 \mathrm{~K}$ & 0.22638 & & $7.20 \mathrm{E}-04$ & 0.00648 & 0.99239 \\
\hline \multirow[t]{6}{*}{ Page } & & $\mathbf{k}$ & $\mathbf{n}$ & & & \\
\hline & $353 \mathrm{~K}$ & 0.03414 & 1.16567 & $5.27 \mathrm{E}-05$ & 0.00158 & 0.99924 \\
\hline & $363 \mathrm{~K}$ & 0.05136 & 1.14043 & $4.28 \mathrm{E}-05$ & 0.00107 & 0.99943 \\
\hline & $373 \mathrm{~K}$ & 0.08077 & 1.15162 & $9.67 \mathrm{E}-05$ & 0.00155 & 0.99879 \\
\hline & $383 \mathrm{~K}$ & 0.12537 & 1.10208 & $1.97 \mathrm{E}-04$ & 0.00236 & 0.99759 \\
\hline & $393 \mathrm{~K}$ & 0.18174 & 1.14522 & $2.25 \mathrm{E}-04$ & $1.80 \mathrm{E}-03$ & $9.99 \mathrm{E}-01$ \\
\hline \multirow[t]{6}{*}{ Modified Page } & & $\mathbf{k}$ & $\mathbf{n}$ & & & \\
\hline & $353 \mathrm{~K}$ & 0.05518 & 1.16599 & $5.27 \mathrm{E}-05$ & 0.00158 & 0.99924 \\
\hline & $363 \mathrm{~K}$ & 0.07403 & 1.14002 & $4.28 \mathrm{E}-05$ & 0.00107 & 0.99943 \\
\hline & $373 \mathrm{~K}$ & 0.11249 & 1.15155 & $9.67 \mathrm{E}-05$ & 0.00155 & 0.99879 \\
\hline & $383 \mathrm{~K}$ & 0.15196 & 1.10195 & $1.97 \mathrm{E}-04$ & 0.00236 & 0.99759 \\
\hline & $393 \mathrm{~K}$ & 0.22562 & 1.14479 & $2.25 \mathrm{E}-04$ & 0.0018 & 0.99762 \\
\hline \multirow[t]{6}{*}{$\begin{array}{c}\text { Henderson } \\
\text { and Pebis }\end{array}$} & & $\mathbf{a}$ & $\mathbf{k}$ & & & \\
\hline & $353 \mathrm{~K}$ & 1.04392 & 0.0575 & $3.87 \mathrm{E}-04$ & 0.0116 & 0.99439 \\
\hline & $363 \mathrm{~K}$ & 1.04645 & 0.07788 & $2.31 \mathrm{E}-04$ & 0.00577 & 0.99693 \\
\hline & $373 K$ & 1.04138 & 0.11771 & 4.07E-04 & 0.0065 & 0.9949 \\
\hline & $383 \mathrm{~K}$ & 1.02584 & 0.15658 & $3.63 \mathrm{E}-04$ & 0.00435 & 0.99556 \\
\hline & $393 \mathrm{~K}$ & 1.03465 & 0.23501 & 5.72E-04 & 0.00457 & 0.99396 \\
\hline
\end{tabular}


Table 4 (continue)

\begin{tabular}{cccccccc}
\hline Equation & Temp.(K) & & & & Reduced, $X^{2}$ & RSS & Adj. $R^{2}$ \\
\hline $\begin{array}{c}\text { Singh and } \\
\text { Wang }\end{array}$ & & $\mathbf{a}$ & $\mathbf{b}$ & & & & \\
\hline & $353 \mathrm{~K}$ & -0.04468 & $5.56 \mathrm{E}-04$ & & $2.05 \mathrm{E}-05$ & $6.16 \mathrm{E}-04$ & 0.9997 \\
& $363 \mathrm{~K}$ & -0.06154 & 0.00109 & & $5.04 \mathrm{E}-05$ & 0.00126 & 0.99933 \\
& $373 \mathrm{~K}$ & -0.0927 & 0.00245 & & $6.38 \mathrm{E}-05$ & 0.00102 & 0.9992 \\
& $383 \mathrm{~K}$ & -0.12789 & 0.00476 & & $6.13 \mathrm{E}-05$ & $7.35 \mathrm{E}-04$ & 0.99925 \\
& $393 \mathrm{~K}$ & -0.1884 & 0.0102 & & $1.33 \mathrm{E}-04$ & 0.00106 & 0.99859 \\
\hline Logarithmic & & $\mathbf{a}$ & $\mathbf{k}$ & $\mathbf{c}$ & & & \\
\hline & $353 \mathrm{~K}$ & 1.21969 & 0.04085 & -0.20557 & $5.94 \mathrm{E}-05$ & 0.00172 & 0.99914 \\
& $363 \mathrm{~K}$ & 1.10363 & 0.06741 & -0.07277 & $1.36 \mathrm{E}-04$ & 0.00326 & 0.99819 \\
& $373 \mathrm{~K}$ & 1.1294 & 0.09592 & -0.10766 & $2.11 \mathrm{E}-04$ & 0.00316 & 0.99735 \\
& $383 \mathrm{~K}$ & 1.07066 & 0.13986 & -0.05545 & $3.12 \mathrm{E}-04$ & 0.00344 & 0.99618 \\
& $393 \mathrm{~K}$ & 1.08303 & 0.20869 & -0.05849 & $5.23 \mathrm{E}-04$ & 0.00366 & 0.99447 \\
\hline Decay & & $\mathbf{a}$ & $\mathbf{b}$ & $\mathbf{c}$ & & & \\
\hline & $353 \mathrm{~K}$ & 0.89654 & 0.11 & 0.05 & $1.68 \mathrm{E}-05$ & $4.86 \mathrm{E}-04$ & 0.99976 \\
& $363 \mathrm{~K}$ & 0.87489 & 0.14 & 0.07 & $2.05 \mathrm{E}-05$ & $4.91 \mathrm{E}-04$ & 0.99973 \\
& $373 \mathrm{~K}$ & 0.88186 & 0.13 & 0.10 & $5.08 \mathrm{E}-05$ & $7.63 \mathrm{E}-04$ & 0.99936 \\
& $383 \mathrm{~K}$ & 0.86006 & 0.14 & 0.14 & $6.56 \mathrm{E}-05$ & $7.22 \mathrm{E}-04$ & 0.9992 \\
& $393 \mathrm{~K}$ & 0.87696 & 0.13 & 0.21 & $5.91 \mathrm{E}-05$ & $4.13 \mathrm{E}-04$ & 0.99937 \\
\hline
\end{tabular}

The capability of the model is based on the value of $X^{2}$, RSS and adjusted $R^{2}$. The absolute mathematical model has indicated the highest value in $R^{2}$, lowest reduced $X^{2}$ and lowest RSS. The regression coefficients and standard deviations of single-layer drying models for black liquor during infra-red evaporation under the infra-red temperature range of $80-120^{\circ} \mathrm{C}$ are shown in Table 4 . The modified Page and Page equation model was an exponent ' $n$ ' added to the drying constant ' $k$ ', which contributes to the evaporation constant of distinct magnitude. All the models exhibited great concurrence with the IR evaporation data of black liquor. The experimental data of the Decay model in Equation 14 has illustrated the closest fit to the black liquor evaporation for all the infra-red temperature range tested.

$$
X=a+b+\left(0.25 c^{2} t^{2}\right)-\left(a^{0.5} c t\right)
$$

From Equation 14 above, $X$ indicates the moisture fraction and t was signified the evaporation time, respectively. The valued parameters of this model $(a, b$, and $\mathrm{c})$ and values of reduced $X^{2}$, RSS and adjusted $R^{2}$ are emphasised in Table 4 . The Decay model has been stated as the improved fitting evaporation model, which features the highest $R^{2}$, lowest reduced $X^{2}$ and RSS values for the entire infra-red temperature range of 80 to $90^{\circ} \mathrm{C}$. The adjusted $R^{2}$ values were higher than 0.9992 , and reduced $X^{2}$ and RSS values were lower than $6.56 \times 10^{-5} \& 7.63 \times 10^{-4}$, respectively, for the entire infra-red evaporation conditions. 


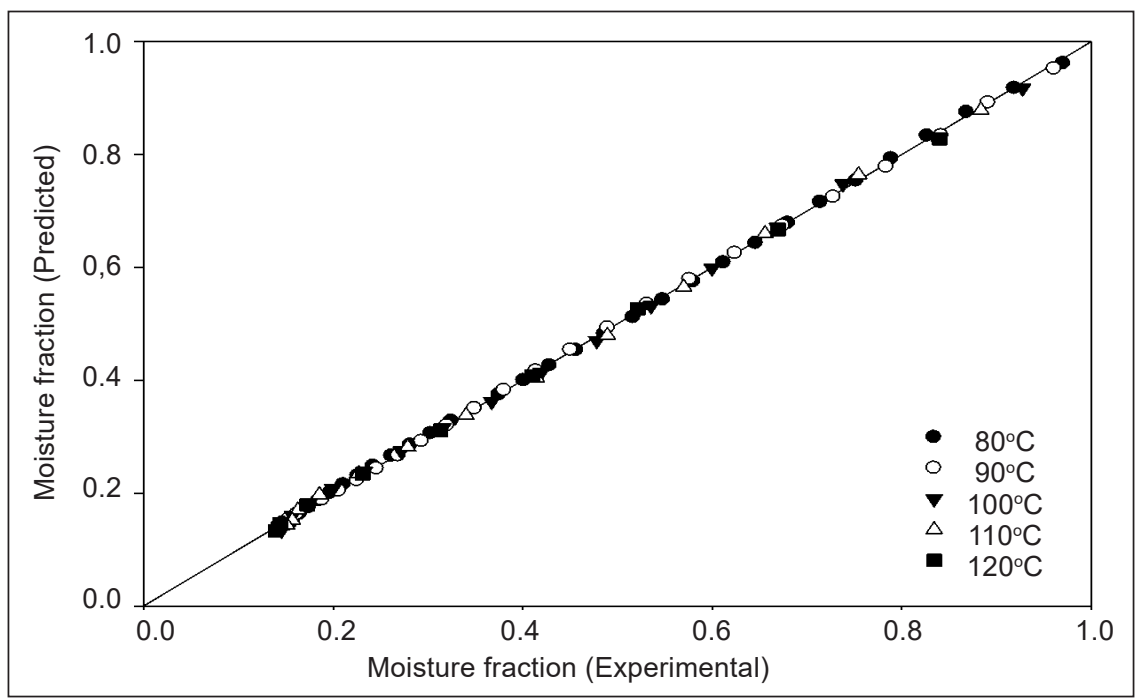

Figure 3. Experimentally determined and predicted moisture fraction of black liquor from Decay model Equation 14.

Although, the fitted evaporation curves based on the Decay model initiated to deliver outstanding fits of the test temperatures of $80,90,100,110$, and $120^{\circ} \mathrm{C}$ shown in Figure 3.

The parameter of the evaporation constants ( $a, b$, and $c)$ in the Decay model indicates that the relative magnitude of the parameter accurately reflects the evaporation behaviour. Meanwhile, the values of the evaporation constants " $a$ " and " $b$ " were in the range of 0.89654-0.86006 and 0.11-0.14 under the infra-red (IR) temperature range of 80-120 $\mathrm{C}$, respectively (Table 4). Moreover, the value of the evaporation constant " $c$ " increased with the increase in infra-red (IR) temperature. Besides, the higher " $c$ " values demonstrate higher moisture removal rates and improve evaporation potential. Thus, though the Decay model could function to simulate the evaporation curves of black liquor with satisfactory test results, in spite the parameters of these models should improvise due to lack of physical sense.

\section{Mathematical Modelling of Evaporation Rate}

The variations of the drying rates versus moisture content are shown in Figure 4. The evaporation rate for black liquor at different temperatures based on Gaussian law Equation 3 was derived from the plot of evaporation rate $(d x / d t)$ versus moisture fraction $(X)$ in Figure 4.

General model Gaussian 3 given by Equation 15,

$$
E R=\frac{d x}{d t}=a_{1} e^{\left(-\frac{x-b_{1}}{c_{1}}\right)^{2}}+a_{2} e^{\left(-\frac{\left(x-b_{2}\right)}{c_{2}}\right)^{2}}+a_{3} e^{\left(-\frac{x-b_{3}}{c_{3}}\right)^{2}}
$$




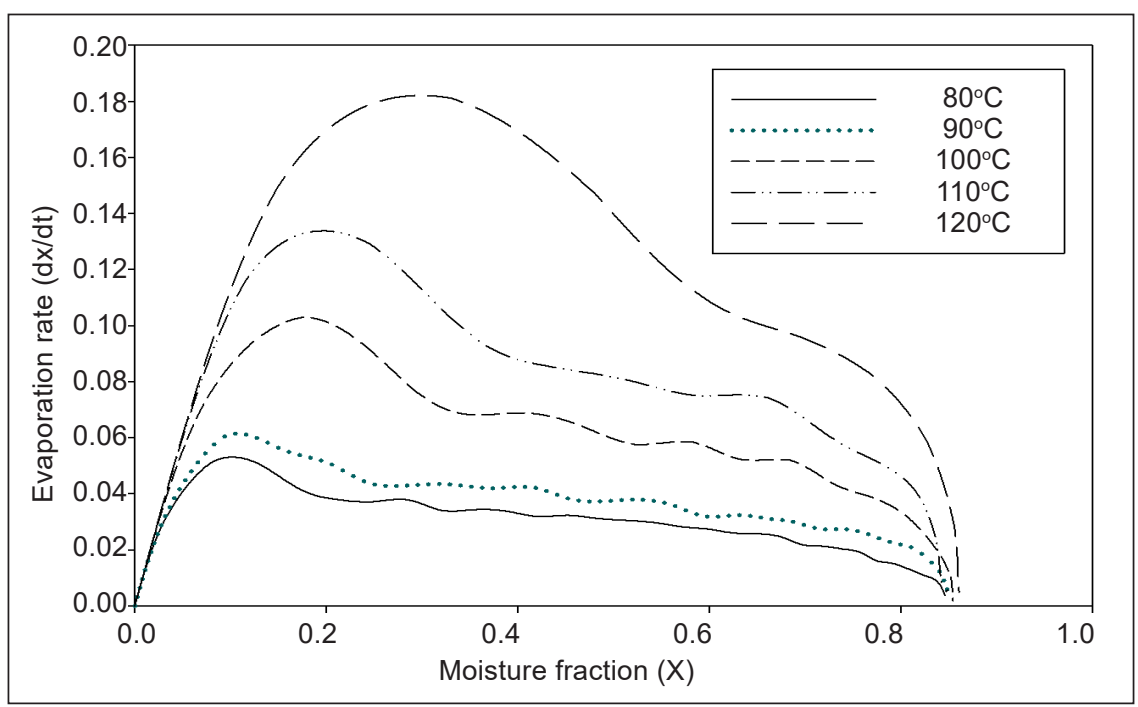

Figure 4. A variance of evaporation rate with a moisture content of black liquor

Table 5

Regression coefficients of black liquor through infra-red evaporation

\begin{tabular}{cccccccccc}
\hline $\begin{array}{c}\text { Temperature } \\
\left({ }^{\mathbf{C}} \mathbf{C}\right)\end{array}$ & $\mathbf{a 1}$ & $\mathbf{b 1}$ & $\mathbf{c 1}$ & $\mathbf{a 2}$ & $\mathbf{b 2}$ & $\mathbf{c 2}$ & $\mathbf{a 3}$ & $\mathbf{b 3}$ & $\mathbf{c 3}$ \\
\hline 80 & 0.0369 & 2.388 & 1.481 & 0.02291 & 6.206 & 4.277 & 0.02881 & 15.99 & 11.91 \\
90 & 0.06368 & 1.374 & 2.734 & -0.08997 & -1.54 & 3.584 & 0.04065 & 9.36 & 13.27 \\
100 & 0.08122 & 1.814 & 1.227 & 0.04908 & 4.199 & 2.434 & 0.05342 & 9.258 & 5.08 \\
110 & -0.4649 & 0.3825 & 0.4103 & -0.7202 & 2.446 & 4.471 & 0.842 & 1.97 & 5.188 \\
120 & $-2.77 \mathrm{E}+13$ & -26.42 & 4.711 & 0.2282 & -1.275 & 6.724 & - & - & - \\
\hline
\end{tabular}

Coefficients (with $95 \%$ confidence bounds)

Table 6

Standard deviations of goodness on fit of Gaussian model for black liquor

\begin{tabular}{ccccc}
\hline Temperature $\left({ }^{\circ} \mathbf{C}\right)$ & SSE & $\boldsymbol{R}^{2}$ & Adjusted $\boldsymbol{R}^{\mathbf{2}}$ & RMSE \\
\hline $\mathbf{8 0}$ & 0.000216 & 0.9614 & 0.949 & $\mathbf{0 . 0 0 2 9 3 9}$ \\
$\mathbf{9 0}$ & 0.000242 & 0.9649 & 0.9501 & $\mathbf{0 . 0 0 3 5 6 7}$ \\
$\mathbf{1 0 0}$ & 0.000361 & 0.9778 & 0.9601 & $\mathbf{0 . 0 0 6 0 1 1}$ \\
$\mathbf{1 1 0}$ & 0.000117 & 0.9954 & 0.9893 & $\mathbf{0 . 0 0 4 4 2 1}$ \\
$\mathbf{1 2 0}$ & $4.23 \mathrm{E}-05$ & 0.9731 & 0.9462 & $\mathbf{0 . 0 0 2 9 0 8}$ \\
\hline
\end{tabular}

The regression coefficient of the Gaussian model Equation 3 is shown in Table 5. The statistical analysis values obtained from fitting the experimental data to the Gaussian model equation is presented in Table 6 . The $R^{2}$, SSE and RMSE values ranged from 0.9614-0.9954, 0.0000423-0.000361 and 0.002908-0.006011 for black liquor, respectively (Table 6). 


\section{Calculation of Effective Diffusivity and Activation Energy}

The effective moisture diffusivity is an important transport property in food and other materials drying processes modelling, being a function of temperature and moisture content in material (Liu et al., 2009). The effective diffusivity and activation energy calculation has indicated that the isothermal condition was founded instantaneously and sustained throughout the evaporation of the black liquor process. In this method, with negligible sample shrinkage and uniform initial moisture distribution assumptions, the $D_{\text {eff }}$ can be defined with an appropriate mathematical solution of Fick's second law for diffusion in Equation 5. Meanwhile, Figure 5 has displayed the plots of the experimental results as $\ln (X)$ versus time, corresponding with different temperatures. The values of the effective moisture diffusivity were calculated using Equation 9 and are shown in Table 5 and Figure 5.

The $D_{\text {eff }}$ values were varied in the range of $2.67 \times 10^{-10} \mathrm{~m}^{2} / \mathrm{s}$ to $10.4 \times 10^{-10} \mathrm{~m}^{2} / \mathrm{s}$ (Table 7). It was noted that $D_{\text {eff }}$ values increased greatly with increasing drying temperature. When samples were dried at a higher temperature, increased heating energy would increase the activity of water molecules leading to higher moisture diffusivity.

Arrhenius plot, $\ln D_{\text {eff }}$ versus $1 /(T+273.15)$ Equation 9. The $\ln D_{\text {eff }}$ as a function of the reciprocal of absolute temperature was plotted in Figure 6. The slope of the line is $\left(-E_{d} / R\right)$, and the intercept equals to $\ln \left(D_{o}\right)$. The activation energy data achieve with formulation from Equation 8. Therefore, the results have displayed with linear relationship shown in Figure 6 due to the Arrhenius-type dependence $\left(R^{2}=0.9651\right)$. Therefore, the linear slope

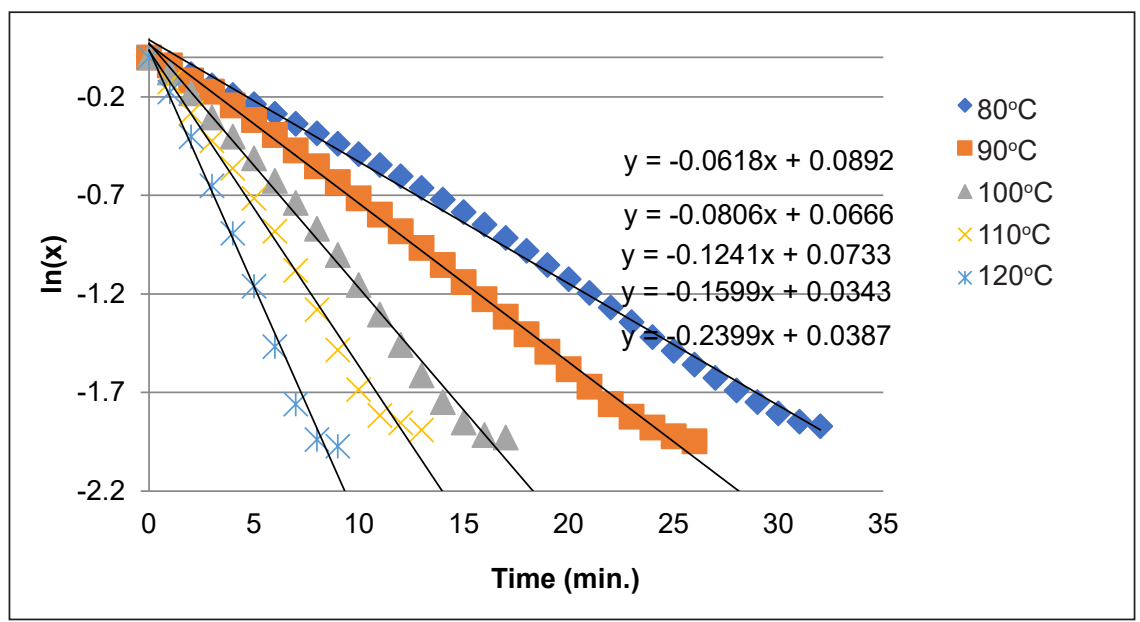

Figure 5. The plot of $\ln X$ versus time for infra-red evaporation of weak black liquor at different temperatures

Table 7

Effective diffusivities of black liquor under the infrared temperature range of $80-120^{\circ} \mathrm{C}$

\begin{tabular}{lccccc}
\hline Temperature $\left({ }^{\circ} \mathrm{C}\right)$ & 80 & 90 & 100 & 110 & 120 \\
\hline$D_{e f f}\left(\mathrm{~m}^{2} / \mathrm{s}\right)$ & $2.67 \times 10^{-10}$ & $3.48 \times 10^{-10}$ & $5.37 \times 10^{-10}$ & $6.93 \times 10^{-10}$ & $10.4 \times 10^{-10}$ \\
\hline
\end{tabular}




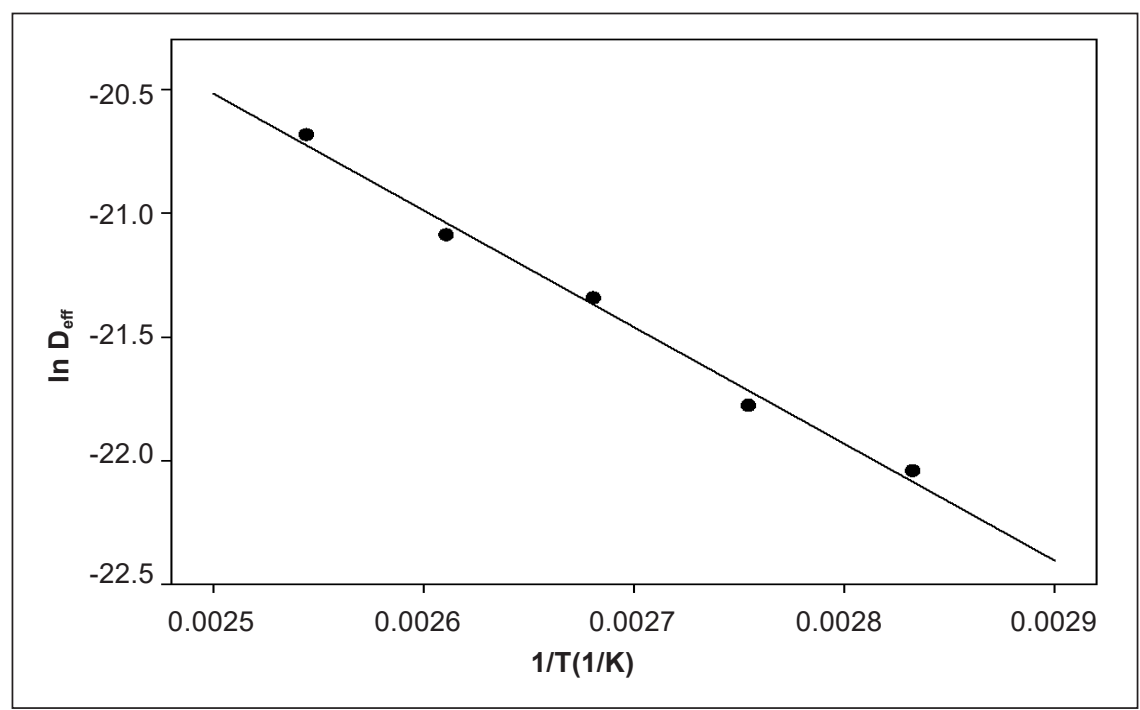

Figure 6. Arrhenius type correlation for temperature and effective diffusivity of black liquor

from the graph has denoted $39.19 \mathrm{~kJ} / \mathrm{mol}$ of activation energy value, and pre-exponential factor $1.6 \times 10^{-4} \mathrm{~m}^{2} / \mathrm{s}$ was determined for evaporation of black liquor. The activation energy values were within the general range of 12.7 to $110 \mathrm{~kJ} / \mathrm{mol}$ for various food materials (Zogzas et al., 1996).

\section{CONCLUSIONS}

The effect of infra-red evaporation temperature on moisture fraction, evaporation rate and effective diffusivity of soda black liquor was studied. Soda black liquor with an initial solids content of 13.5 to $15 \%$ was evaporated to the final moisture fraction approx. 0.025 in 33 minutes at $80^{\circ} \mathrm{C}$, and it is performed within 10 minutes at $120^{\circ} \mathrm{C}$. Increasing the infrared (IR) temperature increased the evaporation rate and consequently decreased the evaporation duration within a certain infrared (IR) temperature range $\left(80-120^{\circ} \mathrm{C}\right.$ in the present investigation). Major evaporation occurred in the falling rate period (FRP). The decay empirical model showed a good fit for all the conditions than the other six thin layer evaporation models for describing soda black liquor's infra-red (IR) evaporation behaviour. The adjusted $R^{2}$ values were higher than 0.9992 , and reduced $R^{2}$ and RSS values were lower than $6.56 \times 10^{-5}$ and $7.63 \times 10^{-4}$, respectively, for the entire infra-red evaporation conditions.

The values of evaporation constant " $a$ " and constant " $b$ " were in the range of 0.89654 to 0.86006 and 0.11 to 0.14 under the infra-red (IR) temperature range of 80 to $120^{\circ} \mathrm{C}$, respectively. The effective moisture diffusivity of black liquor under an infrared temperature range of $80-120^{\circ} \mathrm{C}$ was in the range of $2.6 \times 10^{-10} \mathrm{~m}^{2} / \mathrm{s}$ to $10.4 \times 10^{-10} \mathrm{~m}^{2} / \mathrm{s}$. The experimental results have shown that the moisture diffusivity of black liquor is lower than other organic materials, which could be discovered in the literature under similar evaporation conditions. 


\section{ACKNOWLEDGMENT}

First author thankful to Department of Paper Technology, IIT Roorkee, India, for providing facility to conduct research work.

\section{REFERENCES}

Ahou, K., Emmanuel, A. N., Patrice, K., \& Benjamin, Y. (2014). Modelling of rough rice solar drying under natural convection. European Scientific Journal, 10(3), 141-156.

Alriols, M. G., Tejado, A., Blanco, M., Mondragon, I., \& Labidi, J. (2009). Agricultural palm oil tree residues as raw material for cellulose, lignin and hemicelluloses production by ethylene glycol pulping process. Chemical Engineering Journal, 148(1), 106-114. https://doi.org/10.1016/j.cej.2008.08.008

Amin, N., Sabli, N., Izhar, S., \& Yoshida, H. (2019). Sago wastes and its applications. Pertanika Journal of Science and Technology, 27(4), 1841-1862.

Bajpai, P. (2017). Evaporation of black liquor. In Pulp and Paper Industry (pp. 39-66). Elsevier. https://doi. org/10.1016/b978-0-12-811103-1.00003-6

Bhargava, V. K. (1966). Drying of wheat grain in thin layers (Doctoral dissertation). University of British Columbia, Canada.

Bruce, D. M. (1985). Exposed-layer barley drying: Three models fitted to new data up to $150^{\circ} \mathrm{C}$. Journal of Agricultural Engineering Research, 32(4), 337-348. https://doi.org/10.1016/0021-8634(85)90098-8

Chen, X. D. (2009). On a relationship proposed for thin layer drying of porous materials. Chemical Engineering and Processing: Process Intensification, 48(11-12), 1583-1584. https://doi.org/10.1016/j.cep.2009.10.001

Crank, J. (1975). The mathematics of diffusion. Oxford University Press. https://doi.org/10.1021/ja01562a072

Darvishi, H., Azadbakht, M., Rezaeiasl, A., \& Farhang, A. (2013). Drying characteristics of sardine fish dried with microwave heating. Journal of the Saudi Society of Agricultural Sciences, 12(2), 121-127. https:// doi.org/10.1016/j.jssas.2012.09.002

Datta, A. K., \& Anantheswaran, R. C. (2001). Handbook of microwave technology for food applications. In A. K. Datta \& R. C. Anantheswaran (Eds.), Marcel Dekker, Inc. All Rights Reserved (1st Ed.). Taylor \& Francis. https://doi.org/https://doi.org/10.1201/9781482270778

Do, N. H., Pham, H. H., Le, T. M., Lauwaert, J., Diels, L., Verberckmoes, A., Do, N. H. N., Tran, V. T., \& Le, P. K. (2020). The novel method to reduce the silica content in lignin recovered from black liquor originating from rice straw. Scientific Reports, 10(1), 1-11. https://doi.org/10.1038/s41598-020-77867-5

Gögüs, F., \& Maskan, M. (2001). Drying of olive pomace by a combined microwave-fan assisted convection oven. Nahrung - Food, 45(2), 129-132. https://doi.org/10.1002/1521-3803(20010401)45:2<129::AIDFOOD129>3.0.CO;2-T

Goodell, E. G., \& Point, S. (1933). Black liquor recovery process and apparatus (Patent No. US1931536A). Patented Oct 31, 1933.

Guo, H. (2011). A simple algorithm for fitting a Gaussian function [DSP tips and tricks]. IEEE Signal Processing Magazine, 28(5), 134-137. 
Haghsheno, M., \& Kouhikamali, R. (2020). Numerical investigation of effective parameters of falling film evaporation in a vertical-tube evaporator. Heat Transfer, 50(3), 2764-2792. https://doi.org/10.1002/ htj.22004

Hatibaruah, D., Baruah, D. C., \& Sanyal, S. (2013). Microwave drying characteristics of assam ctc tea (Camellia assamica). Journal of Food Processing and Preservation, 37(4), 366-370. https://doi.org/10.1111/j.17454549.2011.00656.x

Hurter, R. W. (1991). Nonwood plant fiber characteristics. Tappi Press.

Karlsson, E. (2020). Evaluation of sodium salt scaling in black liquor evaporators using existing process data. Nordic Pulp and Paper Research Journal, 35(4), 516-532. https://doi.org/10.1515/npprj-2020-0038

Liu, X., Qiu, Z., Wang, L., Cheng, Y., Qu, H., \& Chen, Y. (2009). Mathematical modeling for thin layer vacuum belt drying of panax notoginseng extract. Energy Conversion and Management, 50(4), 928-932.

Low, E. S., \& Ong, P. (2020). On the formulation of metaheuristic algorithm-based approximation approach for non-linear ordinary differential equations with application to heat exchanger problem. Pertanika Journal of Science and Technology, 28(4), 1221-1265. https://doi.org/10.47836/pjst.28.4.06

Madamba, P. S., Driscoll, R. H., \& Buckle, K. A. (1996). The thin-layer drying characteristics of garlic slices. Journal of Food Engineering, 29(1), 75-97. https://doi.org/10.1016/0260-8774(95)00062-3

Meziane, S., Kadi, H., \& Lamrous, O. (2006). Kinetic study of oil extraction from olive foot cake. Grasas y Aceites, 57(2), 175-179. https://doi.org/10.3989/gya.2006.v57.i2.34

Mujumdar, A. S. (2007). Book review: Handbook of industrial drying (3rd Ed.). Drying Technology, 25(6), 1133-1134. https://doi.org/10.1080/07373930701399224

Naqvi, M., Yan, J., \& Dahlquist, E. (2010). Black liquor gasification integrated in pulp and paper mills: A critical review. Bioresource Technology, 101(21), 8001-8015. https://doi.org/10.1016/j.biortech.2010.05.013

Nasir, N. A. F. M., Jamaluddin, J., Zainudin, Z., Busheri, M. M., Adrus, N., Azim, F. S. S., \& Hasham, R. (2020). The effect of alkaline treatment onto physical, thermal, mechanical and chemical properties of Lemba leaves fibres as new resources of biomass. Pertanika Journal of Science and Technology, 28(4), 1531-1547. https://doi.org/10.47836/pjst.28.4.21

Overhults, D. G., White, G. M., Hamilton, H. E., \& Ross, I. J. (1973). Drying soybeans with heated air. Transactions of the American Society of Agricultural Engineers, 16(1), 112-113. https://doi. org/10.13031/2013.37459

Ranganathan, A. (2004). The levenberg-marquardt algorithm. Tutoral on LM algorithm, 11(1), 101-110.

Sandu, C. (1986). Infrared radiative drying in food engineering: A process analysis. Biotechnology Progress, 2(3), 109-119. https://doi.org/10.1002/btpr.5420020305

Sanjuán, N., Lozano, M., García-Pascual, P., \& Mulet, A. (2003). Dehydration kinetics of red pepper (Capsicum annuum L var Jaranda). Journal of the Science of Food and Agriculture, 83(7), 697-701. https://doi. org/10.1002/jsfa. 1334

Thakor, N. J., Sokhansanj, S., Sosulski, F. W., \& Yannacopoulos, S. (1999). Mass and dimensional changes of single canola kernels during drying. Journal of Food Engineering, 40(3), 153-160. https://doi.org/10.1016/ S0260-8774(99)00042-4 
Tütüncü, M. A., \& Labuza, T. P. (1996). Effect of geometry on the effective moisture transfer diffusion coefficient. Journal of Food Engineering, 30(3-4), 433-447. https://doi.org/10.1016/s02608774(96)00028-3

Yagcioglu, A. K., Degirmencioglu, A., \& Cagatay, F. (1999, May 26). Drying characteristics of laurel leaves under different drying conditions. In 7th International Congress on Agricultural Mechanization and Enerdy (pp. 565-569). Adana, Turkey.

Zogzas, N. P., Maroulis, Z. B., \& Marinos-Kouris, D. (1996). Moisture diffusivity data compilation in foodstuffs. Drying Technology 14(10), 2225-2253. https://doi.org/10.1080/07373939608917205 